17

\title{
О фотостабильности акрилатных и полиметилметакрилатных планарно-волоконных структур с люминофорами Coumarin 7, 47, 120; POPOP; NOL8 для ультрафиолетовых информационных систем
}

\author{
(C) А.В. Бритвин ${ }^{1}$, Н.С. Никитенко ${ }^{1}$, В.Ф. Плюснин ${ }^{2}$, Б.В. Поллер ${ }^{1,39}$, А.Б. Поллер ${ }^{1}$, Н.В. Шахов ${ }^{1,3}$ \\ ${ }^{1}$ Институт лазерной фризики Сибирского отделения РАН, \\ 630090 Новосибирск, Россия \\ ${ }^{2}$ Институт химической кинетики и горения Сибирского отделения РАН, \\ 630090 Новосибирск, Россия \\ ${ }^{3}$ Новосибирский государственный технический университет, \\ 630087 Новосибирск, Россия \\ ฯe-mail: lablis@mail.ru
}

Поступила в редакцию 14.06.2021 г.

В окончательной редакции 14.06.2021 г.

Принята к публикации 12.11.2021 г.

Выполнены исследования при длительном ультрафиолетовом (УФ) облучении фотоустойчивости планарно-волоконных структур в виде пленок толщиной 600-800 $\mu \mathrm{m}$ из особо чистого полиметилметакрилата (ПММА) и из акриловой смолы, в которые вводились люминофоры Coumarin 7, 47, 120; POPOP, NOL8. Люминофор NOL12 (КНЛ12) находился в полимерных волокнах производства ООО „Технологический центр полимерного оптического волокн“. К торцам пленок присоединялись волоконные световоды из ПММА, с выхода которых измерялась мощность излучения люминесценции в зависимости от мощности и времени УФ облучения. Показана перспективность применения люминофоров типа Coumarin для использования планарно-волоконных структур в УФ информационных системах в качестве приемных антенн для оптических телекоммуникаций и оптических сенсоров для мониторинга физических полей.

Ключевые слова: фотостабильность, планарно-волоконные структуры, люминофоры, информационные системы.

DOI: $10.21883 /$ OS.2022.02.52001.2201-21

\section{Введение}

Полимерные структуры с добавкой люминофоров активно исследуются для создания солнечных концентраторов, полимерных лазеров, сцинтилляторов, сенсорных и информационных устройств. Освоение ультрафиолетовых (УФ) полупроводниковых излучателей стимулировало интерес к УФ атмосферным системам связи и мониторинга.

Так, специалистами АО „НИИПП“ и ИЛФ СО РАН были разработаны экспериментальные образцы УФ диодов (один, два и четыре кристалла в корпусе) на 0.36 и $0.38 \mu \mathrm{m}$. Функционирование информационных систем значительно улучшается при использовании планарноволоконных структур (ПВС), имеющих большую площадь сбора УФ фотонов и волоконные линии для передачи излучения люминесценции.

Энергия фотонов в УФ диапазоне значительно больше, чем в ИК диапазоне, что позволяет использовать полимерные нанофотонные системы с люминофорами для преобразования спектральных, временных и энергетических характеристик УФ импульсов.

Полимерные ПВС могут иметь площадь приема фотонов до нескольких сотен квадратных сантиметров при толщине пленки до долей миллиметра и могут применяться на наземных и воздушных объектах вместо сложных и громоздких линзовых или зеркальных систем для оптических телекоммуникаций и контроля.

Наиболее известные первые зарубежные работы по применению полимерных структур с люминофорами начаты в 2014-2016 г. [3-5]. Основным направлением исследования является возможность применения данных антенн в сетях связи видимого диапазона [6].

В ИЛФ СО РАН возможность применения ПВС для приемных антенн в системах связи и контроля исследуется с 2000 г. [1,2]. Значительные возможности открывают ПВС для построения УФ телекоммуникаций с подвижными объектами, особенно с беспилотными летательными аппаратами (БПЛА) и для ретрансляторов наземно-космической связи [2,7-12].

В ИЛФ СО РАН в 2002 г. разработаны и испытаны полимерные волоконные антенны с люминофорами для приема в УФ диапазоне речевой информации на дальности до $400 \mathrm{~m}$, полимерные пленочные и волоконные антенны с люминофорами для радиозондов для УФ связи со спутниками и для контроля УФ радиации от Солнца на высотах до $25 \mathrm{~km}[8,11]$.

В общем случае преобразование ПВС УФ импульса мощностью $P_{0}$ со спектром $S_{0}$ и длительностью $T_{0}$ описываются следующими операторами: $Q\{\}, F\{\}, W\{\}$. 
Мощность импульса на выходе ПВС определяется

$$
P_{\text {out }}=Q\left\{P_{0} ; j ; \Pi ; G\right\},
$$

где $j$ - квантовая эффективность используемого люминофора, П - ослабление в используемом полимере, $G$ - конфигурация и свойства пленок и волокон для сбора и передачи фотонов люминесценции.

Спектр выходного импульса определяется оператором

$$
S_{\text {out }}=F\left\{S_{0} ; Y ; R ; V\right\}
$$

где $Y$ - параметр сдвига спектра в длинноволновую область из-за люминесценции, $R$ - спектральные характеристики используемых полимеров, $V$ - форма спектра люминесценции используемого люминофора.

Длительность выходного импульса

$$
T_{\text {out }}=W\left\{T_{0} ; t_{\text {exc }} ; t_{\text {ext }}\right\} \text {, }
$$

где $t_{\text {ехс }}$ - время возбуждения используемого люминофоpa (до долей ns), $t_{\mathrm{ext}}$ - параметры расширения импульса в пленках и волокнах.

Вопросы построения оптимальных ПВС с учетом данных операторов рассмотрены в наших публикациях $[1,5,6]$. Однако свойства операторов могут значительно меняться во времени из-за длительного воздействия рабочего оптического сигнала и длительного воздействия солнечного излучения на люминофоры и на полимерную пленку. Поэтому анализ влияния таких воздействий на эффективность люминесценции и спектральные характеристики люминесценции является актуальной задачей.

\section{Материалы и методика эксперимента}

Для размещения люминофоров в полимерных пленках пригодны полимеры, имеющие малые оптические потери на рабочих длинах волн в УФ, видимом и ИК диапазонах. Полимеры не должны деградировать при длительном воздействии оптических рабочих сигналов, при воздействии солнечных излучений и погодных условий.

После исследования нами ряда оптических полимеров (силиконовая резина, полипропилен, эпоксидные смолы, акриловые смолы, полиметилметакрилат) с различными люминофорами для синтеза ПВС были выбраны полиметилметакрилат (ПММА) и акриловые смолы. Пленки из них с люминофорами РОРОР и Радомин 6G были успешно испытаны на шарах — радиозондах для контроля облачности и УФ радиации на высотах до $26 \mathrm{~km}[9]$.

Однако испытания таких пленок при воздействии солнечного излучения в течении десятков часов показали значительную деградацию этих люминофоров. Вместе с тем пленка из ПММА после годовой солнечной засветки в высокогорных условиях сохранила оптическую прозрачность. В настоящее время применяются две технологии изготовления пленок. Из ПММА (применяемого для изготовления полимерных световодов) пленка изготавливается путем растворения гранул ПММА в особо чистом дихлорэтане и дальнейшем высушивании и термопрессовании. В раствор с ПММА добавляются различные люминофоры и наночастицы в оптимальном количестве.

Пленка из жидкой акриловой смолы (применяемой для изготовления автомобильных стекол - триплексов) синтезируется в вакууме при УФ облучении. В раствор со смолой добавляются различные люминофоры и наночастицы.

В связи с поиском фотоустойчивых люминофоров большой интерес и возможности представляют новые кремнийорганические люминофоры, созданные в Институте синтетических полимерных материалов и производимых организацией ООО „ЛюмИнноТех“ [13]. На основе люминофора NOL8 (представленном ООО „ЛюмИнноТех“) и ранее использовавшихся люминофоров РОРОР и Coumarin 7, 47, 120 были изготовлены полимерные пленки с одинаковыми параметрами. Для исследований фотоустойчивости при солнечном облучении использовались также полимерные волокна диаметром $0.5 \mathrm{~mm}$ с введенным в них NOL12, из которых изготавливались плоские сборки волокон для солнечной засветки.

Методика исследований состояла из двух частей. Первая часть направлена на измерения спектральных характеристик пленок с люминофорами с помощью стандартных приборов. Вторая часть потребовала разработку стенда для длительного УФ облучения и солнечного облучения пленок с различными люминофорами и измерения выхода люминесценции с торца пленки с помощью волоконного световода и измерителя оптической мощности.

\section{Спектральные характеристики ПВС}

Спектры люминесценции при облучении пленки на длине волны $313 \mathrm{~nm}$ представлены на рис. 1 .

Ширина спектра люминесценции NOL8 значительно шире, чем у РОРОР и кумаринов.

В Институте химической кинетики и горения СО РАН была исследована кинетика люминофоров в акриловой пленке (рис. 2).

Возбуждение NOL8 производилась на $375 \mathrm{~nm}$ (диодный лазер с импульсом длительностью 60 ps). Регистрация осуществлялась на длине волны $445 \mathrm{~nm}$. Обработка в трехэкспоненциальном приближении дает времена $0.175 \mathrm{~ns}(12.4 \%$ испущенных квантов), $1.51 \mathrm{~ns}(57.2 \%)$ и $6.95 \mathrm{~ns}(30.4 \%)$.

Также следует отметить изменение распределения спектра люминесценции от времени облучения. Для NOL8 спектр люминесценции на выходе волновода при облучении светодиодом на $370 \mathrm{~nm}$ отличается от 


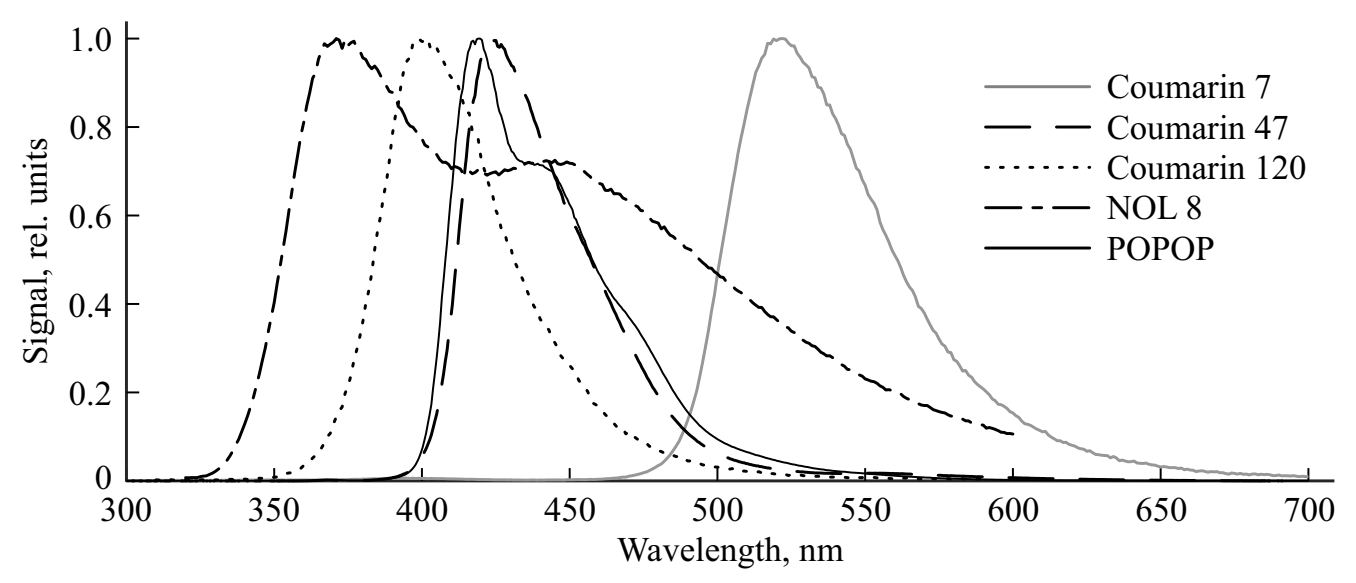

Рис. 1. Спектры люминесценции.

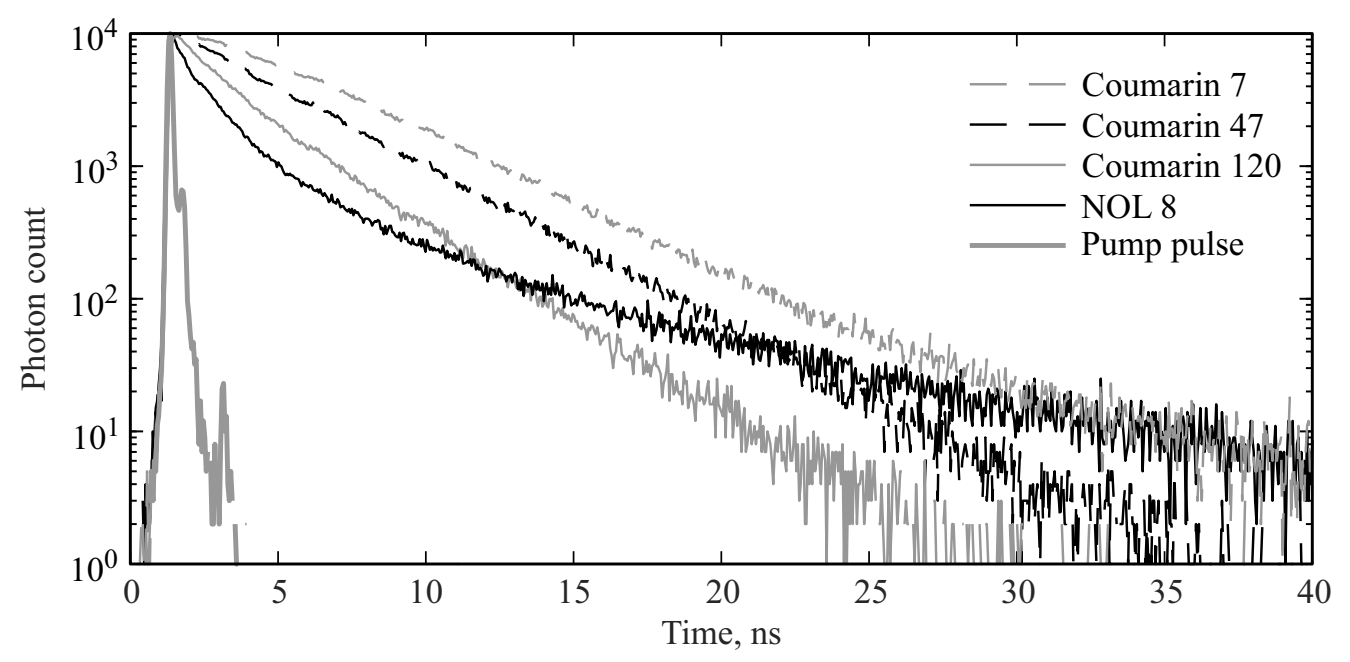

Рис. 2. Кинетика люминесценции в акриловой пленке.

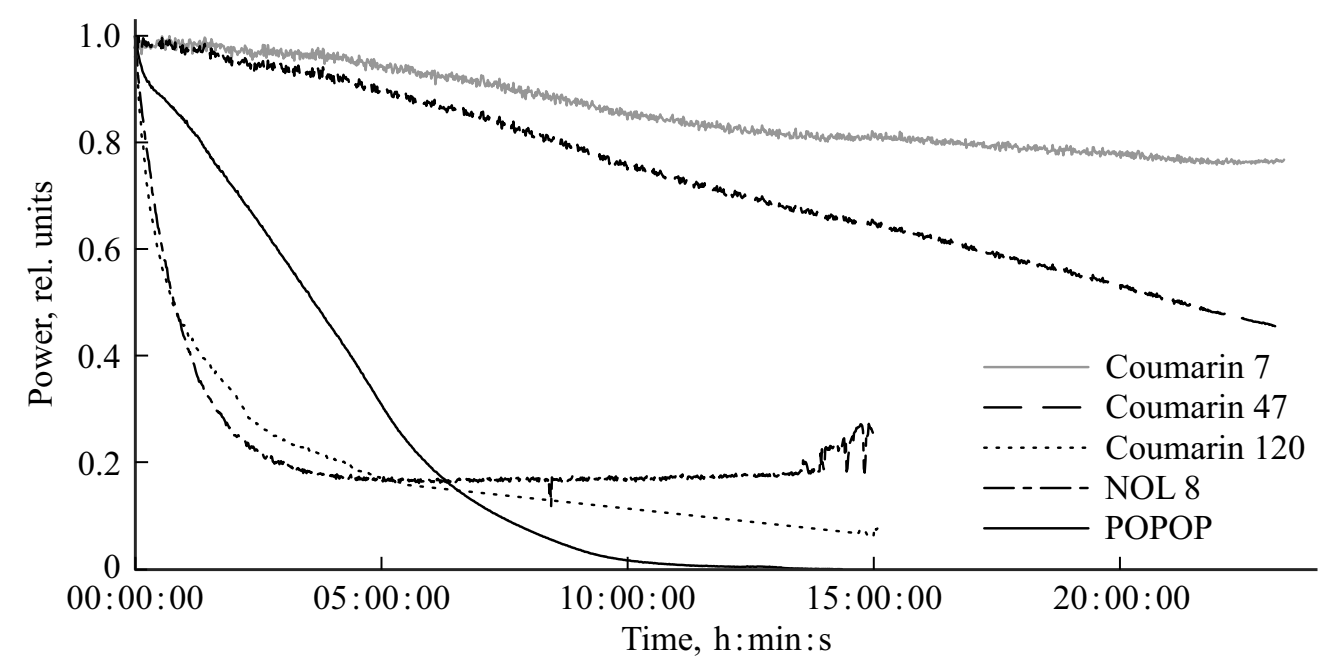

Рис. 3. Изменение выхода люминесценции с торца волновода от времени облучения (чч:мм:сс). 

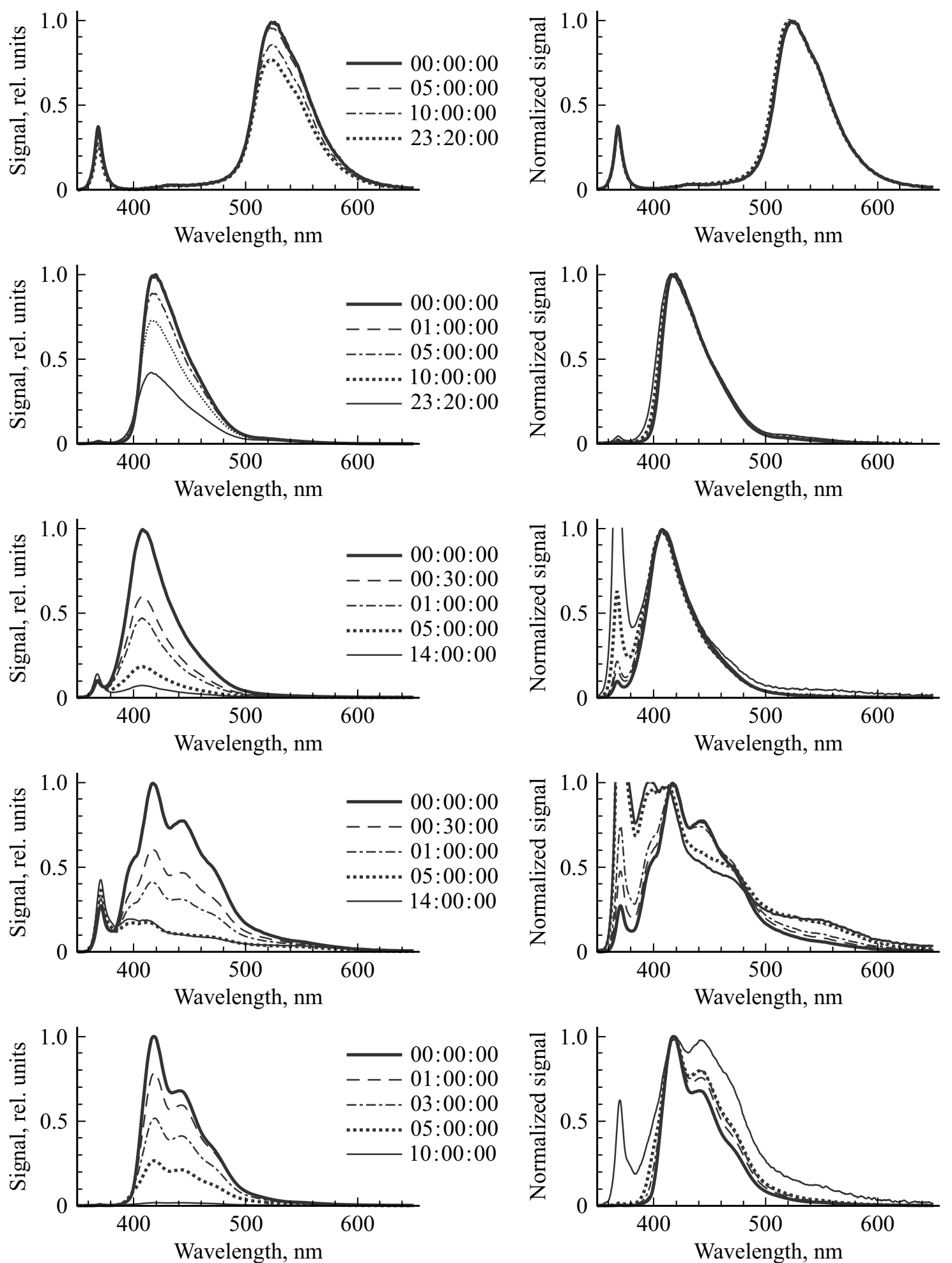

Pис. 4. Изменение спектра люминесценции от времени облучения. $a-$ Coumarin $7, b-$ Coumarin $47, c-$ Coumarin $120, d-$ NOL $8, e-$ POPOP.

спектра люминесценции при облучении на $313 \mathrm{~nm}$. Распределение спектров люминесценции NOL8, POPOP, Coumarin 47 для различных времен облучения представлены на рис. 4. В представленных спектрах присутствует излучение светодиода.

\section{Характеристики фотоустойчивости при длительном УФ и солнечном облучении}

Для оценки продолжительности работы ПВС на атмосферных трассах были проведены исследования фото- 
устойчивости к УФ излучению ПВС с люминофорами NOL8, POPOP и Coumarin на стенде в лабораторных условиях и при солнечном облучении на стенде на крыше пятиэтажного здания Института в Академгородке Новосибирска.

Для оценки фотоустойчивости боковая поверхность планарного волновода из ПММА длительно облучалась УФ светодиодом с длиной волны $365 \mathrm{~nm}$ таким образом, чтобы вся площадь волновода была облучена равномерно с плотностью мощности $3 \mathrm{~W} / \mathrm{m}^{2}$. Излучение люминесценции, выходящее с торца пленки через волоконный зонд, периодически измерялось измерителем оптической мощности Newport.

Был выбран уровень облученности пленок с люминофором в десятки раз больше реальной облучённости на атмосферных трассах от удаленных УФ передатчиков. Изменение уровня выходной люминесценции с торцов пленок при облучении в течении $50 \mathrm{~h}$ показало, что наиболее заметное падение выходного излучения приходится на первые два часа облучения. Выходная мощность за этот период с пленки с люминофором РОРОР упала на $23.8 \%$, с пленки с люминофором NOL8 - на $18.5 \%$. 3a $150 \mathrm{~h}$ мощность люминесценции от пленки с РОРОР уменьшилась на $70 \%$, мощность от пленки с NOL8 на $80 \%$. Удовлетворительная аппроксимация на плавном участке снижения излучения от времени на интервалах времени до $500 \mathrm{~h}$ была выполнена по формуле:

$$
P_{\text {lum }}=P_{0} \exp (-\alpha t)
$$

где $P_{\text {lum }}-$ мощность, выходящая с торцов пленок, $P_{0}-$ подаваемая на пленку мощность, $t-$ время облучения пленки, $\alpha-$ экспоненциальный коэффициент.

Для POPOР приближенно $\alpha=0.01 \mathrm{~h}^{-1}$, для NOL8 $\alpha=0.011 \mathrm{~h}^{-1}$, для Coumarin $47 \alpha=0.0004 \mathrm{~h}^{-1}$.

Также были выполнены эксперименты с облучением в течении $500 \mathrm{~h}$ пленок с люминофором типа Coumarin 47, 120 , которые показали снижение выхода излучения после длительного облучения ориентировочно не более чем на $20 \%$.

Учитывая, что ПВС может применяться при условии солнечной засветки, были выполнены сеансы длительного прямого солнечного облучения пленок на крыше здания в июне и июле 2020 г. При этом пленки с РОРОР, NOL8 и матрица из волокон с NOL12 значительно снизили люминесценцию после пребывания на Солнце (с максимальной освещенностью до $130000 \mathrm{~lx}$ ) в течении 4-5 days. Пленки с люминофорами Coumarin 7, 47, 120 показали незначительное снижение выхода люминесценции после 10 days пребывания на интенсивном Солнце. При дополнительной спектральной защите ПВС с помощью оптических фильтров уровень солнечной засветки снижается в десятки раз, и тем самым значительно увеличивается время работы ПВС на Солнце. Учитывая, что пленки в аппаратуре будут эксплуатироваться со значительно меньшей УФ облученностью и с устройствами защиты от дождя и от засветок, можно прогнозировать непрерывное время работы ПВС в течении нескольких лет (при необходимости со сменой кассет с ПВС в выносных антенных устройствах). Данный вывод подтверждается положительным опытом эксплуатации люминофоров типа Coumarin в люминофорных солнечных концентраторах [14].

Использование в аппаратуре выносных антенн из диэлектрических ПВС с диэлектрическим оптическим кабелем позволяет аппаратуре работать также при сильных электромагнитных помехах и в условиях искро- и взрывоопасности.

\section{Выводы}

1. Пленки из чистого ПММА и из акрилатов с люминофорами Coumarin 47, 120 обладают фотоустойчивостью по отношению к облучению $3 \mathrm{~W} / \mathrm{m}^{2}$ на длине волны $365 \mathrm{~nm}$ и также по отношению к длительной солнечной засветке.

2. На базе пленок из ПММА с фотоустойчивым люминофором Coumarin 47 с потенциальной пропускной способностью до $1 \mathrm{Gibit/s}$ были разработаны и успешно испытаны планарно-волоконные антенны для аппаратуры атмосферной УФ связи, пригодной также для работы в условиях сильных электромагнитных помех, в искрои взрывоопасных условиях.

\section{Конфликт интересов}

Авторы заявляют, что у них нет конфликта интересов.

\section{Список литературы}

[1] A.A. Golubenkov, A.I.'Karapuzikov, B.V. Poller, W.F.Plyusnin. Characteristics of ultraviolet gas-discharge emitter and polimeric spectrum transformers for laser telecommunications (MPLP, Novosibirsk, 2000).

[2] С.Н. Багаев, Б.В. Поллер, А.В. Бритвин и др. In: Maтериалы 11 Международной конференции Проблемы бункционирования информационных сетей“ СО РАН (Новосибирск, 2006), с. 22-26.

[3] S. Collins, D.C. O’Brien, A. Watt. Opt. Lett., 39, 1756-1759 (2014).

[4] P.P. Manousiadis, S. Rajbhandari, R. Mulyawan, D.A. Vithanage, H. Chun, G. Faulkner, D.C. O’Brien, G.A. Turnbull, S. Collins, I.D.W. Samuel. Optica, 3 (7), $702-706$ (2016).

[5] T. Peyronel, K.J. Quirk, S.C. Wang, T.G. Tiecke. Optica, 3 (7), 787-792 (2016).

[6] S. Zvanovec, P. Chvojka, P.A. Haigh, Z. Ghassemlooy. Radioengineering, 24 (1), 1 ?9 (2015).

[7] А.В. Бритвин, А.Б. Поллер, Б.В. Поллер, А.Е. Кусакина. Интерэкспо Гео-Сибирь, 5 (2), 22-26 (2012).

[8] Б.В. Поллер, А.В. Бритвин, Б.Д. Борисов, В.Ф. Плюснин и др. Проблемы информатики, 1, 69-75 (2013).

[9] Б.В. Поллер, А.В. Бритвин, Б.Д. Борисов, В.Ф. Плюснин. Интерэкспо Гео-Сибирь, 5 (3), 77-80(2013).

[10] А.В. Бритвин, Н.С. Никитенко, В.Ф. Плюснин, Б.В. Поллер. Интерэкспо Гео-Сибирь, 2 (5), 211-221 (2018). 
[11] А.В. Бритвин, Ю.Д. Коломников, Н.С. Никитенко, В.Ф. Плюснин, Б.В. Поллер, А.Б. Поллер, Ю.И. Щетинин. Интерэкспо Гео-Сибирь, 5 (2), 106-110 (2017).

[12] Б.В. Поллер, А.В. Бритвин, С.И. Коняев, Ю.И. Щетинин. Гео-Сибирь, 5 (2), 64-68 (2011).

[13] ООО „ЛюмИнноТех“ [Электронный ресурс]. URL: https://luminnotech.com/ru/produktsiya/phosphors

[14] А.В. Бритвин, С.И. Коняев, Н.С. Никитенко, А.В. Поважаев, Б.В. Поллер, Ю.И. Щетинин. Радиотехника, 1, 25-28 (2019). 